\title{
MARKETING STRATEGY ANALYSIS KOPI ARABIKA SPECIALTY (STUDI KASUS PADA CV FRINSA AGROLESTARI)
}

\author{
Achmad Fadillah $^{1}$, Yasmin Nabila Salsabila ${ }^{2}$, Arief Daryanto ${ }^{3}$ \\ 1,2,3Sekolah Bisnis, Institut Pertanian Bogor (IPB University), Bogor \\ Email: achmadfadillah@apps.ipb.ac.id
}

KETERANGAN ARTIKEL

Riwayat Artikel

Diterima: 1 Mei 2019

Direvisi : 1 Juni 2019

Disetujui: 31 Juni 2019

Klasifikasi JEL

M30, M31

Keywords: specialty coffee, marketing strategy, IFE-EFE matrix, SWOT matrix

Kata kunci: kopi specialty, strategi pemasaran, matriks IFE-EFE, matriks SWOT

\section{ABSTRACT}

CV Frinsa Agrolestari is a family business engaged in the plantation and specialty coffee bean processing, however this company does not have an optimal domestic marketing strategy yet. This research was conducted to formulate the right domestic marketing strategy for CV Frinsa Agrolestari. Internal and external Environmental factor analysis is carried out using the Internal Factor Evaluation (IFE), External Factor Evaluation (EFE), and InternalExternal (IE) matrices followed by strategy formulation using the SWOT matrix. The design of marketing strategies for specialty coffee beans at CV Frinsa Agrolestari are to carry out continuous product development, ecotourism and edutourism business expansion as a marketing medium, downstream coffee business ecpansion, internet usage optimization as a marketing medium, intensive communication with consumers and shipping services, development of safer packaging designs, educating consumers about product quality, and optimizing the production and business processes development.

\section{ABSTRAK}

CV Frinsa Agrolestari merupakan sebuah bisnis keluarga yang bergerak di bidang perkebunan dan proses biji kopi yang saat ini berfokus pada biji kopi specialty, disisi lain perusahaan tersebut belum memiliki strategi pemasaran yang optimal di pasar domestik. Oleh karena itu, penelitian ini dilakukan untuk merancang strategi pemasaran yang tepat untuk CV Frinsa Agrolestari di pasar domestik. Analisis faktor lingkungan internal dan eksternal dilakukan dengan menggunakan matriks Internal Factor Evaluation (IFE), External Factor Evaluation (EFE), dan Internal-Eksternal (IE) dilanjutkan dengan perancangan strategi menggunakan matriks SWOT. Rancangan strategi pemasaran biji kopi specialty untuk pasar domestik pada CV Frinsa Agrolestari adalah melakukan pengembangan produk secara terus-menerus, pengembangan bisnis ke ekowisata dan eduwisata sebagai media pemasaran, pengembangan bisnis kopi hilir, pengoptimalan penggunaan internet sebagai media pemasaran, komunikasi yang intensif dengan konsumen dan jasa ekspedisi, pengembangan desain kemasan yang lebih aman, edukasi konsumen mengenai kualitas produk, dan pengoptimalan pengembangan proses produksi dan bisnis. 


\section{PENDAHULUAN}

Indonesia menempati urutan keempat terbesar di dunia sebagai produsen dan eksportir komoditas kopi setelah Brasil, Vietnam, dan Kolombia (International Coffee Organization, 2019). Komoditas kopi sangat berkaitan langsung dengan gaya hidup masyarakat saat ini dimana dapat dilihat pada fenomena bertumbuhnya bisnis kedai kopi di Indonesia (Herlyana, 2012). Konsumsi kopi di Indonesia mengalami peningkatan sebesar 2.7 persen (compound annual growth rate) pada periode 2014 - 2018 (International Coffee Organization, 2019).

Peningkatan jumlah konsumsi kopi tersebut mendorong produsen kopi memenuhi permintaan permintaan kopi tersebut. Salah satu jenis biji kopi yang mengalami peningkatan permintaan konsumen adalah kopi arabika berkualitas tinggi yang dikategorikan sebagai kopi specialty.

Salah satu produsen kopi Indonesia yang concern pada produksi kopi specialty adalah $\mathrm{CV}$ Frinsa Agrolestari. CV Frinsa Agrolestari terletak di dataran tinggi Kabupaten Bandung, Jawa Barat. CV Frinsa Agrolestari adalah sebuah perusahaan keluarga yang bergerak di bisnis produksi kopi, mulai dari pembibitan, penanaman, pengolahan hingga menjadi biji kopi, bahkan pemuliaan varietas kopi. CV Frinsa Agrolestari memfokuskan produksinya pada berbagai macam kopi specialty dengan kualitas tinggi dan beragam jenis kopi nusantara.

Peningkatan pada jumlah konsumsi dan permintaan terhadap kopi specialty domestik di Indonesia tentunya menjadi peluang pasar bagi para produsen kopi. Namun, peluang pasar domestik kopi specialty tersebut belum mampu dimanfaatkan dengan optimal oleh CV Frinsa Agrolestari. Selama ini CV Frinsa Agrolestari lebih berfokus dan sangat tergantung pada pasar ekspor. Oleh karena itu, CV Frinsa Agrolestari memerlukan rancangan strategi pemasaran yang tepat untuk kondisi pasar domestic kopi specialty di Indonesia. Berdasarkan latar belakang dan permasalahan diatas, maka penelitian ini bertujuan untuk mengidentifikasi faktor-faktor lingkungan internal dan eksternal yang berpengaruh terhadap pemasaran kopi specialty, serta menyusun alternatif strategi pemasaran biji kopi specialty di pasar domestik untuk CV Frinsa Agrolestari.

\section{KAJIAN LITERATUR \\ Kopi Specialty}

Menurut Yusianto (2013), specialty coffee merupakan produk kopi yang memiliki nilai dan citra unggul yang dipasarkan secara khusus sebagai pembeda dari produk kopi umum lainnya. Beberapa hal yang menjadi karakteristik specialty coffee, meliputi: memiliki cita rasa spesial, memiliki histori sejarah yang unik, memiliki kualitas yang baik, dan harga yang lebih tinggi dibanding dengan produk kopi pada umumnya. Sepulveda, dkk (2016) juga menyatakan bahwa specialty coffee memiliki karakteristik khusus berupa kandungan dan sistem produksi yang bertujuan untuk menghasilkan kopi berkualitas tinggi yang optimal di pasar internasional. Menurut Specialty Coffee Association (SCA) (2018), kopi specialty adalah biji kopi arabika yang memiliki skor cupping 85 sampai dengan 100 dan jumlah defects atau cacat sebanyak 5 persen.

\section{Manajemen dan Bauran Pemasaran}

Menurut Kotler dan Amstrong (2012), strategi pemasaran merupakan strategi dalam memilih segmentasi, posisi dan target pasar. Selain itu, strategi pemasaran dapat juga diartikan sebagai bentuk upaya meraih, mempertahankan, dan menambahkan pelanggan melalui penyampaian nilai utama dan jual dari produk dan jasa kepada konsumen. Sedangkan, manajemen pemasaran yaitu kegiatan mengenali dan mengomersialkan kebutuhan konsumen sehingga menghasilkan penjualan yang sebanyak-banyaknya. Kotler, dkk (2017) menyatakan bahwa terdapat pergeseran pemasaran dari pemasaran tradisional yang berfokus pada product-driven maketing kepada pemasaran digital yang lebih berfokus pada 
customer-driven marketing. Lo dan Campos (2018) menyatakan bahwa pemasaran yang dilakukan perusahaan saat ini harus dapat memanfaatkan internet of things (IOT) dalam menyusun strategi pemasaran yang terkait dengan hubungan langsung dengan konsumen. Pelsmacker, dkk (2018) juga menyatakan bahwa strategi pemasaran digital mempengaruhi kinerja perusahaan terutama jasa.

\begin{tabular}{llrr}
\multicolumn{1}{c}{ Kotler } & dan Amstrong & (2012) \\
mendefinisikan & marketing & mix & (bauran \\
pemasaran) & merupakan & perpaduan \\
seperangkat alat pemasaran untuk
\end{tabular}
mendapatkan konsumen di pasar. Suatu upaya yang dapat dilakukan oleh perusahaan untuk mempengaruhi permintaan dan keputusan konsumen adalah dengan melakukan identifikasi dan analisis bauran pemasaran berdasarkan pendekatan 4P, yaitu product, price, place, dan promotion.

Pada perkembangan konsep bauran pemasaran saat ini telah disesuaikan berdasarkan kondisi bisnis yang berkembang. Menurut Plume, dkk (2017), mengungkapkan bahwa adanya perkembangan konsep bauran pemasaran dari awal dikenalkannya konsep dari McCarthy (1960) dengan elemen 4P (price, product, place, promotion) serta dikenalkan kembali oleh Kotler dan Keller (2012) dengan penekanan pada perbedaan atribut dan referensi nilai produk dari persepsi konsumen. Selanjutnya menurut Plume, dkk (2017) juga menyatakan bahwa Booms dan Bitner (1981) melakukan ektensi pengembangan model $4 \mathrm{P}$ menjadi 7P, dimana terdapat tambahan komponen atribut people, processes, dan physical evidence pada bauran pemasaran karena adanya keterlibatan konsumen khususnya dalam bisnis jasa. Hennig-Thurau dkk (2010) menambahkan bahwa terdapat perubahan dalam proses komunikasi dengan konsumen yang berawal dari satu arah menjadi dua arah, adanya co-creation dalam pembuatan produk berupa interaksi dan hubungan dengan konsumen. Selanjutnya,
Kotler, dkk (2017) menyatakan bahwa bauran pemasaran dapat dikembangkan dan disesuaikan dengan konsep pemasaran terkini (marketing 4.0) yang menekankan kepada perkembangan bisnis digital menjadi konsep bauran pemasaran $4 \mathrm{C}$. Kelompok variabel yang dikembangkan dalam bauran pemasaran $4 \mathrm{C}$ meliputi co-creation, currency, communal activation, dan conversation. Co-creation adalah strategi pengembangan produk yang dilakukan dengan pengembangn bersama dan melibatkan pelanggan di tahap awal ideasi. Currency mengacu pada konsep penetapan harga yang dinamis (dynamic pricing). Communal activation menggunakan konsep peer-to-peer distribution yaitu memberikan akses yang mudah kepada konsumen ke produk dan layanan yang tidak dimiliki oleh perusahaan tetapi oleh konsumen lain. Conversation mengacu kepada konsep komunikasi atas produk perusahaan dengan dibantu oleh teknologi.

Beberapa penelitian terkait strategi pemasaran kopi telah dilakukan sebelumnya. Ganda (2003) menyatakan bahwa terdapat beberapa faktor yang mempengaruhi pemasaran kopi, yaitu: preferensi konsumen terhadap kopi dengan aroma dan rasa yang khas serta jaminan mutu, harga produk kopi, dan kepraktisan. Sedangkan menurut Jati (2006) dalam penelitiannya menyatakan bahwa faktor kekuatan berupa bahan baku bermutu tinggi, proses pengolahan berorientasi kualitas mutu, dan faktor peluang berupa tren konsumsi bio-coffee dan dukungan dari pemerintah setempat merupakan faktor utama dalam strategi pemasaran kopi arabika di Semarang. Selanjutnya Nurlaeli (2018) menyatakan bahwa jumlah produksi dan kualitas kopi arabika, semakin banyaknya kedai kopi, serta perkembangan agrowisata menjadi faktor pendukung strategi pengembangan agribisnis kopi di Kabupaten Banjarnegara. Menurut Anugerah (2019) menyatakan bahwa faktor internal utama dalam pemasaran kopi meliputi: penyediaan produk specialty coffee, 
kesesuaian citarasa dengan harga kopi yang ditawarkan, dan promosi serta faktor eksternal utama meliputi perubahan gaya hidup, perkembangan teknologi, peningkatan daya beli konsumsi, dan peningkatan jumlah coffee shop.

\section{METODE PENELITIAN}

\section{Rancangan Penelitian}

Rancangan penelitian ini dilakukan dengan meliputi beberapa tahap, yaitu analisis strategi pemasaran awal yang diterapkan oleh CV Frinsa Agrolestari, identifikasi faktor internal dan eksternal perusahaan, formulasi strategi, dan rekomendasi strategi pemasaran terbaru. Analisis strategi pemasaran awal dilakukan dengan mengidentifikasi atribut pemasaran product, price, place, dan promotion yang sudah dilakukan CV Frinsa Agrolestari. Selanjutnya, dilakukan identifikasi faktor internal berupa kekuatan dan kelemahan serta faktor eksternal berupa peluang dan ancaman sebagai dasar pemetaan matriks IE dan SWOT. Hasil dari matriks SWOT digunakan untuk menyusun rekomendasi strategi pemasaran berbasis pemasaran 4.0 dengan pengembangan atribut co-creation, currency, communal activation, dan conversation.

\section{Teknik Pengumpulan Data}

Teknik non probability sampling berupa teknik purposive sampling digunakan untuk memilih responden penelitian. Teknik ini digunakan karena sesuai dengan rancangan penelitian dimana sampel responden yang diambil berdasarkan kriteria yang telah tentukan, seperti responden harus memahami dengan baik proses bisnis CV Frinsa Agrolestari dan bisnis kopi specialty. Adapun populasi dari penelitian ini adalah seluruh karyawan CV Frinsa Agrolestari untuk reponden internal dan pemilik coffee shop untuk reponden eksternal. Sampel responden internal dipilih berdasarkan jenis tanggung jawab pekerjaannya yang berhubungan dengan aktivitas pemasaran dan penjualan di CV Frinsa Agrolestari. Responden internal terdiri atas Bapak Wildan Mustofa (Pemilik CV Frinsa Agrolestari), Ibu Atieq Mustikaningtyas (Manajer Pemasaran CV Frinsa Agrolestari), dan Bapak Fikri Raihan Hakim (Staf Sales CV Frinsa Agrolestari). Responden ekternal konsumen dipilih berdasarkan jenis usahanya, yaitu roastery house yang menjual produknya ke konsumen akhir dan kedai kopi lain, kedai kopi yang melakukan aktivitas pemanggangan kopi untuk penggunaan usahanya sendiri, serta bisnis kopi berskala besar (korporasi) yang memanggang kopi nya untuk digunakan di usahanya sendiri dan juga dijual secara ritel. Sedangkan responden eksternal ahli dipilih dengan pertimbangan bidang keahlian di bidang industri kopi Indonesia. Responden ekternal konsumen terdiri atas Bapak Dendi Hendra (Pemilik "Journey Roastery"), Bapak Asep Sultani (Direksi "Armor Kopi"), dan Bapak Arnold Dharmmadhyaksa (Senior Manager "Paberik Kopi Upnormal Coffee Roasters") serta responden eksternal ahli Bapak Daroe Handojo (General Manager Coffee Busines PT Cita Rasa Prima Group "Paberik Kopi Upormal Coffee Roasters").

\section{Metode Analisis Data}

Metode analisis data yang digunakan dalam penelitian ini adalah metode kualitatif. Adapun alat analisis yang digunakan meliputi: 1) analisis marketing mix 4P (product, price, place, promotion, 2) identifikasi faktor internal/IFE (Internal Factor Evaluation) dan eksternal/EFE (External Factor Evaluation), 3) memetakan Internal-External (IE) matrix, serta 4) analisis SWOT (Strength - Weakness Opportunity - Threat) berdasarkan pendekatan marketing mix 4C (co-creation, currency, communal activation, dan conversation).

Analisis marketing mix (bauran pemasaran) historis CV Frinsa Agrolestari menggunakan konsep pemasaran Kotler dan Amstrong (2012). Selanjutnya, untuk analisis IFE dan EFE menggunakan konsep strategi David (2011). Menurut David (2011), untuk mengkaji, mengidentifikasi, dan menganalisis 
rangkaian strengths dan weaknesses apa saja yang dimiliki oleh suatu bisnis atau perusahaan dapat dilakukan dengan teknik Internal Factor Evaluation (IFE). Sedangkan, untuk merumuskan faktor-faktor luar apa saja (opportunities dan threats) yang mempengaruhi proses suatu bisnis atau perusahaan berdasarkan aspek sosial, ekonomi, budaya, kebijakan, teknologi, dan lainnya dapat menggunakan teknik External Factor Evaluation (EFE). Analisis IFE dan EFE kemudian disajikan dalam bentuk matriks yang dapat dilihat pada Tabel 1.

Tabel 1. Matriks IFE dan EFE

\begin{tabular}{lccc}
\hline $\begin{array}{c}\text { Faktor Internal } \\
\text { Utama }\end{array}$ & Bobot & Rating & Skor \\
\hline Kekuatan & & $3-4$ & \\
\hline Kelemahan & & $1-2$ & \\
\hline Total & 1.00 & & \\
\hline $\begin{array}{c}\text { Faktor Eksternal } \\
\text { Utama }\end{array}$ & Bobot & Rating & Skor \\
\hline $\begin{array}{c}\text { Peluang } \\
\text { Ancaman }\end{array}$ & & $1-4$ & \\
\hline Total & 1.00 & $1-4$ & \\
\hline
\end{tabular}

Sumber: David (2011)

Hasil identifikasi faktor lingkungan tersebut kemudian disusun dalam matriks IE (Gambar 1), yaitu sebuah matriks yang memosisikan suatu organisasi ke dalam sembilan sel untuk mengetahui posisi strategi yang sudah dilakukan oleh perusahaan dan strategi apa yang perlu dilakukan selanjutnya (David 2011). Matriks IE memiliki tiga bagian yang terbagi dalam sembilan sel. Setiap bagian tersebut memiliki implikasi strategi yang berbeda, yaitu sel I, II, dan IV yang disebut grow and build; sel III, V, dan VII yang disebut hold and maintain; serta sel VI,VIII, dan IX yang disebut harvest and divest.

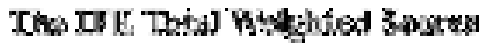

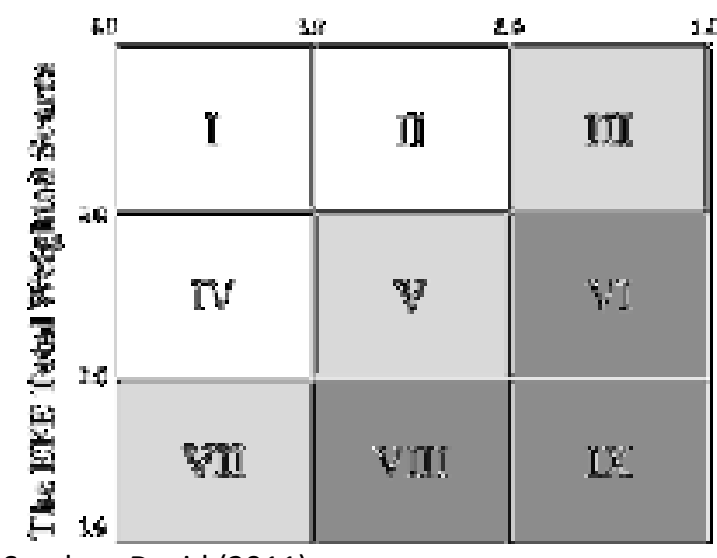

Sumber: David (2011)

Gambar 1. Matriks IE

Selanjutnya, untuk menetapkan strategi yang akan disarankan, hasil analisis faktor lingkungan yang telah didapatkan disusun dalam matriks SWOT (Tabel 2). Menurut David (2011), matriks SWOT membantu pengembangan strategi dengan cara memasangkan setiap faktor-faktor lingkungan internal dan eksternal sehingga menghasilkan empat tipe strategi, yaitu SO strategy (perpaduan antara kekuatan dan peluang), WO strategy (perpaduan antara kelemahan dan peluang), ST strategy (perpaduan antara kekuatan dan ancaman) dan WT strategy (perpaduan antara kelemahan dan ancaman). Matriks SWOT yang telah disususn digunakan sebagai panduan untuk merancang strategi pemasaran CV Frinsa Agrolestari.

Tabel 2. Matriks SWOT

\begin{tabular}{|c|c|c|}
\hline $\begin{array}{c}\text { Peluang } \\
\text { Eksternal }\end{array}$ & $\begin{array}{c}\text { Kekuatan } \\
\text { (Strengths) }\end{array}$ & $\begin{array}{c}\text { Kelemahan } \\
\text { (Weaknesses) }\end{array}$ \\
\hline $\begin{array}{c}\text { (Onportunities) } \\
\text { Strategi SO }\end{array}$ & Strategi WO \\
\hline (Threats) & Strategi ST & Strategi WT \\
\hline
\end{tabular}

Sumber: David (2011) 
Rancangan perbaikan strategi pemasaran CV Frinsa Agrolestari dilakukan dengan menggunakan konsep $4 \mathrm{C}$ pemasaran 4.0 (Kotler, 2017). Konsep 4C terdiri atas cocreation, currency, communal activation, dan conversation.

\section{HASIL DAN PEMBAHASAN}

\section{Gambaran Umum Perusahaan}

CV Frinsa Agrolestari merupakan sebuah perusahaan keluarga yang bergerak pada bisnis komoditas kopi, mulai dari pembibitan, pemuliaan varietas kopi, penanaman, pengolahan hingga pemasaran biji kopi. CV Frinsa Agrolestari yang berdiri sejak 2011 memfokuskan produksinya pada berbagai macam kopi specialty dengan kualitas tinggi dan beragam jenis kopi Nusantara. Visi CV Frinsa Agrolestari adalah "Best Coffee from Best Practices", yang berkomitmen untuk memproduksi kopi specialty berkualitas dengan menggunakan praktik perkebunan dan produksi kopi yang berkelanjutan sehingga tidak merugikan lingkungan maupun masyarakat di sekitar lokasi perkebunan dan produksinya. CV Frinsa Agrolestari saat ini memiliki lima orang karyawan tetap yang bertanggungjawab atas kegiatan bisnisnya baik dalam hal administrasi maupun operasional serta sekitar 100-150 orang karyawan musiman.

Produk CV Frinsa Agrolestari yang diberi merek dagang "Java Frinsa Estate" dikelompokkan dalam dua jenis yaitu specialty dan collective. Produk biji kopi specialty terbagi menjadi dua yaitu, single variety dan single estate yang merupakan produk kopi yang ditanam langsung oleh CV Frinsa Agrolestari. Sedangkan, Frinsa Collective adalah biji kopi yang ditanam oleh mitra petani dari CV Frinsa Agrolestari. Selain varian biji kopi berdasarkan jenis dan asal biji kopi, CV Frinsa Agrolestari juga melakukan berbagai macam pemrosesan, diantaranya fully wash, wet hull, natural, dan honey.

Biji kopi single variety merupakan biji kopi yang terdiri atas satu varietas kopi dari berbagai blok perkebunan kopi CV Frinsa Agrolestari. Terdapat enam varian untuk biji kopi single variety yaitu Andung Sari, P88, Ateng Super, Sigarar Utang, Borbor, dan Lini S. Sedangkan biji kopi single estate merupakan biji kopi yang terdiri atas berbagai varietas kopi yang terdapat dalam satu blok kebun CV Frinsa Agrolestari. Terdapat dua varian untuk biji kopi single estate yaitu Weninggalih yang berlokasi di Kecamatan Sindangkerta, Kabupaten Bandung Barat dan Gunung Tilu yang berlokasi di Kecamatan Pangalengan, Kabupaten Bandung.

\section{Bauran Pemasaran Historis (4P) CV Frinsa Agrolestari \\ Product}

Produk biji kopi specialty CV Frinsa Agrolestari yaitu Single Variety dan Single Estate telah diproses dengan standar internasional Specialty Coffee Association (SCA). Standar dari SCA tersebut adalah biji kopi arabika yang memiliki skor cupping 85 sampai 100 dan jumlah defects atau cacat kurang dari 5 persen. Serta Standar Nasional Indonesia (SNI), yaitu SNI 01-2907-2008 untuk produk biji kopi Frinsa Collective. Standar SNI 01-29072008 adalah biji kopi arabika yang memiliki nilai defect atau cacat maksimum 11. Standar tersebut memastikan produk biji kopi dari CV Frinsa Agrolestari memiliki kualitas yang terjamin.

Saat ini, pabrik pemrosesan biji kopi CV Frinsa Agrolestari memiliki kapasitas mesin terpasang mencapai 1000 ton per tahunnya. Akan tetapi karena keterbatasan bahan baku buah kopi (buah kopi), CV Frinsa Agrolestari baru mampu memanfaatkan kapasitas tersebut sebanyak 100 sampai 150 ton saja per tahunnya atau 10-15 persen dari kapasitas mesin produksinya saja. Dengan kapasitas pemrosesan yang sangat tinggi tersebut, CV Frinsa Agrolestari juga menerima jasa pemrosesan biji kopi bagi pengusaha biji kopi lainnya (maklun). 
Price

Harga produk CV Frinsa Agrolestari ditetapkan dengan dipengaruhi oleh berbagai faktor baik produksi, kondisi pasokan, maupun kondisi pasar. Oleh karena itu, harga dari produk biji kopinya selalu berubah dari waktu ke waktu. CV Frinsa Agrolestari menyediakan berbagai ukuran kemasan biji kopi yang, yaitu mulai dari kemasan 1 kg, 3 kg dan 5 kg untuk processor kopi berskala kecil serta kemasan 30 kg dan 80 kg untuk processor kopi berskala besar. Harga kopi specialty yang dijual oleh CV Frinsa Agrolestari berada pada kisaran $\mathrm{Rp}$ 180.000 - Rp 220.000 per kg.

\section{Place}

Konsumen CV Frinsa Agrolestari didominasi oleh konsumen ekspor. Sehingga, channel yang digunakan menggunakan sarana online. Proses pemesanan dan pembelian produk biji kopi specialty CV Frinsa Agrolestari selama ini banyak dilakukan melalui media sosial yaitu Whatsapp dan Instagram. Metode ini dianggap cukup memenuhi kebutuhan pemesanan baik bagi konsumen maupun staff sales CV Frinsa Agrolestari. Selain itu, CV Frinsa Agrolestari juga aktif dalam mengikuti berbagai kegiatan forum dan komunitas di industri kopi Indonesia maupun internasional.

\section{Promotion}

CV Frinsa Agrolestari telah menggunakan media sosial Instagram dan website sebagai media pemasarannya. Namun, penggunaan media tersebut masih belum dioptimalkan. Selama ini, CV Frinsa Agrolestari hanya menggunakan akun Instagram untuk membagikan ulang unggahan dari akun lain yang berisikan tentang CV Frinsa Agrolestari dan masih jarang membagikan informasi langsung mengenai CV Frinsa Agrolestari maupun produknya. Website milik CV Frinsa Agrolestari (www.javafrinsaestate.com) juga masih belum digunakan secara optimal. Promosi yang dilakukan selama ini banyak menggunakan media promosi melalui keikutsertaan dalam berbagai forum kopi seperti kompetisi, lelang, pameran, dan kegiatan gathering komunitas kopi lainnya. Media promosi tersebut selama ini mempermudahkan pertemuan antara produsen kopi dengan konsumen serta mitra potensial.

\section{Analisis Faktor Lingkungan Perusahaan}

Berdasarkan hasil wawancara dengan manajemen CV Frinsa Agrolestari (khususnya bagian pemasaran), yaitu Pemilik CV Frinsa Agrolestari, Manajer Pemasaran CV Frinsa Agrolestari, dan Staff Sales CV Frinsa Agrolestari, didapatkan identifikasi kekuatan dan kelemahan yang digunakan dalam analisis strategi pemasaran biji kopi CV Frinsa Agrolestari. Hasil analisis Internal Factor Evaluation (IFE) secara keseluruhan disajikan pada Tabel 3. Penetapan bobot dilakukan oleh responden internal dari CV Frinsa Agrolestari dengan menggunakan matriks perbandingan berpasangan faktor strategi internal yang menghasilkan bobot rata-rata. Sedangkan penentuan rating dilakukan oleh responden internal CV Frinsa Agrolestari yang menghasilkan rating rata-rata. Dari Tabel 3 diketahui bahwa kekuatan utama CV Frinsa Agrolestari adalah product co-creation dengan konsumen dengan skor 0,406 sedangkan kelemahan utama CV Frinsa Agrolesetari adalah penggunaan kapasitas mesin produksi belum optimal dengan skor 0,086. 
Achmad Fadillah: Analisis Market Segmentation ...

Tabel 3. Matriks IFE CV Frinsa Agrolestari

\begin{tabular}{lccc}
\hline \multicolumn{1}{c}{ Faktor Internal Utama } & Bobot & Rating & Skor \\
\hline Kekuatan & & & \\
S1. Hubungan baik dengan mitra & 0.095 & 4 & 0.382 \\
S2. Hubungan baik dengan konsumen & 0.094 & 4 & 0.376 \\
S3. Hubungan baik dengan program sosial & 0.080 & 3 & 0.241 \\
S4. Hubungan baik dengan asosiasi dan komunitas kopi & 0.076 & 4 & 0.303 \\
S5. Proses berbasis value produk & 0.094 & 4 & 0.376 \\
S6. Product co-creation dengan konsumen & 0.102 & 4 & 0.406 \\
S7. Produk sudah memiliki standar SCA dan SNI & 0.097 & 4 & 0.388 \\
S8. Range ukuran kemasan banyak & 0.091 & 4 & 0.364 \\
\hline & & & 2.835 \\
Kelemahan & & & \\
W1. Penggunaan kapasitas mesin produksi belum optimal & 0.086 & 1 & 0.086 \\
W2. Penggunaan website belum optimal & 0.094 & 1 & 0.094 \\
W3. Penggunaan media sosial belum optimal & 0.091 & 1 & 0.091 \\
\hline & & & 0.271 \\
\hline Total & $\mathbf{1 . 0 0 0}$ & & $\mathbf{3 . 1 0 6}$ \\
\hline
\end{tabular}

Sumber: Data primer (diolah) (2019)

Hasil analisis External Factor Evaluation (EFE) secara keseluruhan disajikan pada Tabel 4. Penetapan bobot dilakukan oleh responden internal dari CV Frinsa Agrolestari dengan menggunakan matriks perbandingan berpasangan faktor strategi ekternal yang menghasilkan bobot rata-rata. Sedangkan penentuan rating dilakukan oleh responden internal CV Frinsa Agrolestari yang menghasilkan rating rata-rata. Dapat diketahui dari Tabel 4 bahwa peluang terbesar CV Frinsa Agrolestari adalah pertumbuhan niche market dengan skor 0.711 sedangkan ancaman terbesar CV Frinsa Agrolesetari adalah fluktuasi harga kopi global dengan skor 0.289. Pertumbuhan niche market kopi specialty ini sangat dipengaruhi oleh peningkatan konsumsi kopi domestik di Indonesia selama 2015-2018 dan menjadikan peluang besar bagi pebisnis kopi specialty untuk memasarkan produknya pada pasar domestik. Sedangkan, harga kopi global yang berfluktuasi menjadi ancaman utama bagi CV Frinsa Agrolestari dalam menetapkan harga kopi, karena penetapan harga selama ini ditentukan oleh harga kopi dunia. Harga kopi yang mengalami penurunan akan mempengaruhi keuntungan yang diperoleh saat permintaan kopi tetap dan harga kopi yang mengalami peningkatan akan mempengaruhi tingkat permintaan konsumen yang menurun. 
Tabel 4. Matriks EFE CV Frinsa Agrolestari

\begin{tabular}{lccc}
\hline \multicolumn{1}{c}{ Faktor Eksternal Utama } & Bobot & Rating & Skor \\
\hline Peluang & & & \\
O1. Pertumbuhan niche market & 0.178 & 4 & 0.711 \\
O2. Perkembangan teknologi informasi dan komunikasi & 0.150 & 2 & 0.300 \\
O3. Perkembangan ekowisata dan eduwisata & 0.139 & 2 & 0.278 \\
\hline & & & 1.289 \\
Ancaman & & & \\
T1. Risiko dalam pengiriman & 0.194 & 2 & 0.389 \\
T2. Fluktuasi harga kopi global & 0.144 & 2 & 0.289 \\
T3. Cuaca tidak menentu & 0.194 & 3 & 0.583 \\
\hline & & & 1.261 \\
\hline Total & $\mathbf{1 . 0 0 0}$ & & $\mathbf{2 . 5 5 0}$ \\
\hline
\end{tabular}

Sumber: Data primer (diolah) (2019)

\section{Analisis Matriks Internal Eksternal (IE)}

Pada hasil analisis matriks IFE pada Tabel 3 diperoleh total skor sebesar 3.106 dan hasil analisis matriks EFE pada Tabel 4 diperoleh total skor sebesar 2. Skor IFE dan skor EFE yang telah diperoleh sebelumnya digunakan sebagai dasar analisis posisi CV Frinsa Agrolestari pada matriks internal eksternal (IE). Adapun hasil pemetaan strategi pemasaran CV Frinsa Agrolestari pada Matriks IE disajikan dalam Gambar 2 berikut:

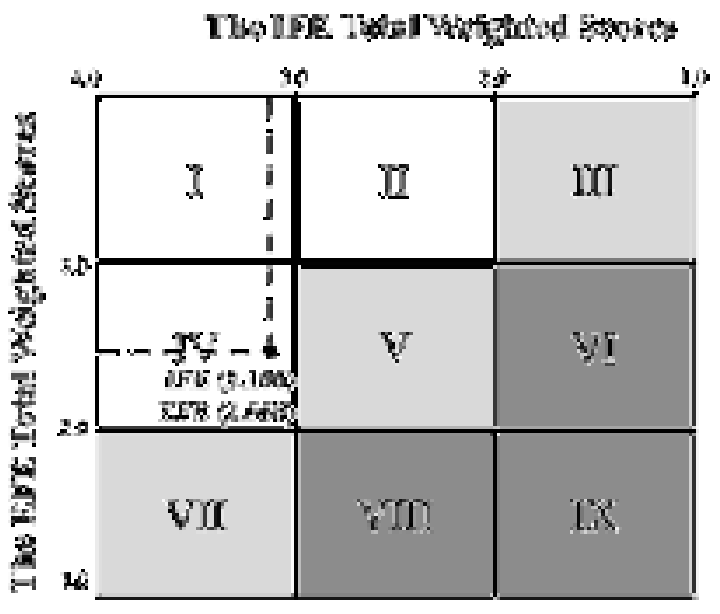

Gambar 2. Matriks IE Strategi

CV Frinsa Agrolestari berada di sel IV (grow and build) sehingga strategi intensif dan strategi integratif merupakan strategi yang dapat disarankan untuk diimplementasikan. Pengembangan produk, pengembangan dan penetrasi pasar merupakan beberapa strategi yang dapat dilakukan sebagai sebuah implikasi upaya strategi intensif. CV Frinsa Agrolestari juga dapat menerapkan strategi integrasi horizontal dan integrasi mundur serta integrasi maju sebagai alternatif strategi. Strategi intensif bertujuan untuk mengembangkan pasar yang sudah ada serta menciptakan pasar baru sehingga perusahaan dapat berkembang dengan lebih baik. Sedangkan strategi integratif seperti integrasi maju, integrasi mundur, dan intergrasi horizontal merupakan strategi yang bertujuan untuk memperkuat rantai pasok perusahaan sehingga proses produksi dan distribusi perusahaan dapat berjalan tanpa hambatan. Strategi yang paling efektif diterapkan oleh CV Frinsa Agrolestari saat ini dalam rangka meningkatkan pemasaran pada pasar domestic adalah dengan melakukan strategi intensif yang bertujuan untuk mengembangkan pasar kopi specialty di Indonesia melalui strategi penetrasi pasar.

\section{Analisis Matriks SWOT berdasarkan Marketing Mix 4C}

Berdasarkan analisis faktor internal (IFE), analisis faktor eksternal (EFE), analisis matriks IE selanjutnya dapat dianalisis alternatif strategi apa saja yang dapat dilakukan oleh CV Frinsa Agrolestari menggunakan matriks SWOT. Analsis matriks SWOT yang dilakukan 
pada penelitian ini berfokus pada strategi pemasaran berdasarkan pendekatan marketing mix 4C. Adapun formulasi strategi berdasarkan matriks SWOT strategi pemasaran (4C) CV Frinsa Agrolestari dapat dilihat pada Tabel 5.

Tabel 5. Matriks SWOT Strategi Pemasaran CV Frinsa Agrolestari

\begin{tabular}{|c|c|c|}
\hline & $\begin{array}{l}\text { Kekuatan } \\
\text { (Strengths) }\end{array}$ & $\begin{array}{l}\begin{array}{c}\text { Kelemahan } \\
\text { (Weaknesses) }\end{array} \\
\text { W1. Penggunaan kapasitas mesin } \\
\text { produksi belum optimal } \\
\text { W2. Penggunaan website belum } \\
\text { optimal } \\
\text { W3. Penggunaan media sosial belum } \\
\text { optimal }\end{array}$ \\
\hline $\begin{array}{l}\text { Peluang } \\
\text { (Opportunities) } \\
\text { O1. Pertumbuhan niche } \\
\text { market } \\
\text { O2. Perkembangan } \\
\text { teknologi informasi } \\
\text { dan komunikasi } \\
\text { O3. Perkembangan } \\
\text { ekowisata dan } \\
\text { eduwisata }\end{array}$ & $\begin{array}{l}\text { Strategi SO } \\
\text { 1. Melakukan pengembangan } \\
\text { produk secara terus-menerus (S1, } \\
\text { S2, S3, S4, S5, S6, S7, S8, O1, O2) } \\
\text { 2. Pengembangan bisnis ekowisata } \\
\text { dan eduwisata sebagai media } \\
\text { pemasaran (S1, S2, S3, S4, S5, O3) } \\
\text { 3. Pengembangan bisnis kopi hilir } \\
\text { (S1, S2, S3, S4, S5, S6, S7, O1) }\end{array}$ & $\begin{array}{l}\text { Strategi WO } \\
\text { 1. Pengoptimalan penggunaan } \\
\text { internet sebagai media pemasaran } \\
(\mathrm{W} 2, \mathrm{~W} 3, \mathrm{O} 1, \mathrm{O} 2)\end{array}$ \\
\hline $\begin{array}{l}\begin{array}{c}\text { Ancaman } \\
\text { (Threats) }\end{array} \\
\text { T1. Risiko dalam } \\
\text { pengiriman }\end{array}$ & $\begin{array}{l}\text { Strategi ST } \\
\text { 1. Komunikasi yang intensif dengan } \\
\text { konsumen dan jasa ekspedisi (S1, } \\
\text { S2, T1) } \\
\text { 2. Pengembangan desain kemasan } \\
\text { pengiriman yang lebih aman (S5, } \\
\text { S8, T1) } \\
\text { 3. Edukasi konsumen mengenai } \\
\text { kualitas produk (S2, S3, S4, S5, S6, } \\
\mathrm{S} 7, \mathrm{~T} 1, \mathrm{~T} 2 \text { ) }\end{array}$ & $\begin{array}{l}\text { Strategi WT } \\
\text { 1. Pengoptimalan pengembangan } \\
\text { proses produksi dan bisnis (W1, } \\
\mathrm{W} 2, \mathrm{~W} 3, \mathrm{~T} 1, \mathrm{~T} 2 . \mathrm{T} 3 \text { ) }\end{array}$ \\
\hline
\end{tabular}

Sumber: data primer yang diolah, 2019

Berdasarkan formulasi strategi yang telah dilakukan didapatkan beberapa strategi pemasaran yang dapat dilakukan oleh CV Frinsa Agrolestari, meliputi:

\section{Strategi SO (Strengths - Opportunities)}

SO1: Melakukan pengembangan produk secara terus-menerus

Strategi ini merupakan pewujudan dari strategi intensif yaitu pengembangan produk serta strategi integrasi yaitu integrasi maju. Hubungan baik antara CV Frinsa Agrolestari dengan mitra, konsumen, program sosial, serta asosiasi dan komunitas kopi akan memudahkan proses implementasi strategi ini. CV Frinsa Agrolestari dapat mengembangkan varian biji kopi baru yaitu biji kopi yang sudah diramu dengan jenis-jenis biji kopi yang sudah ada sehingga memiliki karakteristik-karakteristik tertentu. Pengembangan produk CV Frinsa Agrolestari yang melibatkan konsumen secara aktif dapat dikategorikan perwujudan cocreation dalam pemasaran 4.0. 
SO2: Pengembangan bisnis ekowisata dan eduwisata sebagai media pemasaran

Strategi ini merupakan pewujudan dari upaya penetrasi pasar (strategi intensif) dan upaya integrasi horizontal (strategi integrative). CV Frinsa Agrolestari dapat membangun ekowisata dan eduwisata kopi dengan menggandeng mitra petani kopi, program sosial, dan/atau lembaga pemerintah. Keberadaan ekowisata dan eduwisata ini dapat meningkatkan pengetahuan dan minat masyarakat terhadap produk kopi specialty Indonesia. Hubungan baik antara CV Frinsa Agrolesatari dengan mitra, konsumen, program sosial, serta asosiasi dan komunitas kopi akan memudahkan realisasi dari pengembangan bisnis ekowisata dan eduwisata. Pengembangan bisnis ekowisata dan eduwisata sebagai media pemasaran merupakan pengaplikasian konsep $4 \mathrm{C}$ dari Pemasaran 4.0 yaitu communal activation dan conversation.

\section{SO3: Pengembangan bisnis kopi hilir}

Bisnis B2B seperti CV Frinsa Agrolestari memiliki value tambahan yang terbatas sehingga kurang maksimal profitabilitasnya. Oleh karena itu, pengembangan bisnis kopi hilir yang menjual produknya langsung ke konsumen akhir menjadi pilihan yang baik karena mampu memaksimalkan value tambahan produk yang ditawarkan. CV Frinsa Agrolestari dapat mengembangkan bisnisnya ke bisnis kopi hilir seperti kedai kopi atau roastery house. Hal ini dilakukan agar lebih banyak value dari produk CV Frinsa Agrolestari yang dapat disanpaikan dengan lebih baik ke konsumen. Selain itu, CV Frinsa Agrolestari juga dapat menambahkan value lainnya seperti dalam produk siap konsumsi.

\section{Strategi WO (Weaknesses - Opportunities)}

WO1: Pengoptimalan penggunaan internet sebagai media pemasaran

CV Frinsa Agrolestari saat ini telah memiliki website dan akun Instagram. Namun demikian, penggunaan media tersebut masih belum dimanfaatkan secara optimal oleh CV Frinsa Agrolestari. Website CV Frinsa Agrolestari yang seharusnya dapat dijadikan media pemasaran yang sangat baik, tidak pernah diperbarui. Fitur belanja online di website CV Frinsa Agrolestari juga tidak berfungsi. Sedangkan akun Instagram CV Frinsa Agrolestari masih kurang aktif dan gencar dalam membagikan kontenkonten mengenai produk biji kopi CV Frinsa Agrolestari maupun tentang kopi secara umum.

Keberadaan website dan media sosial mempermudah konsumen untuk melihat informasi relevan mengenai produk-produk CV Frinsa Agrolestari dan nilainya sebagai perusahaan. Untuk melakukan strategi ini pertama-tama diperlukan admin pengelola dan content creator untuk website dan Instagram yang bertanggungjawab untuk membuat konten dan memperbarui informasi yang dibagikan.

Penggunaan internet sebagai media pemasaran merupakan aplikasi dari konsep $4 \mathrm{C}$ co-creation, communal activation, dan conversation dimana peran partisipasi konsumen menjadi poin penting dalam pengembangan bisnis CV Frinsa Agrolestari. Dengan adanya peran aktif konsumen, konsumen akan merasa terlibat dalam perkembangan bisnis dan produk CV Frinsa Agrolestari dan meningkatkan loyalitasnya. Strategi ini merupakan pewujudan dari strategi intensif yaitu pengembangan pasar serta strategi integratif yaitu integrasi maju.

\section{Strategi ST (Strengths - Threats)}

ST1: Komunikasi yang intensif dengan konsumen dan jasa ekspedisi

Strategi ini merupakan pewujudan konsep 4C yaitu communal activation dan conversation, konsumen dan media distribusi (yang dalam hal ini adalah jasa ekspedisi) dilibatkan secara aktif dalam berjalannya proses pengiriman barang. Kerusakan barang dalam pengiriman merupakan risiko yang tidak dapat dipungkiri 
dan harus dihadapi. CV Frinsa Agrolestari harus melakukan komunikasi secara intensif dengan jasa ekspedisi untuk memastikan kondisi barang tejaga selama dalam pengiriman hingga diterima oleh konsumen. Selain itu, komunikasi dengan konsumen juga harus intens untuk memastikan konsumen mengetahui risikorisiko yang ada walaupun penjual sudah mengusahakan yang terbaik agar barang sampai pada pembeli dengan dengan kondisi yang diharapkan. Strategi ini merupakan aplikasi dari strategi integratif yaitu integrasi maju.

ST2: Pengembangan desain kemasan pengiriman yang lebih aman

Strategi ini merupakan pewujudan dari strategi intensif yaitu pengembangan produk. Konsep 4C co-creation dan conversation diwujudkan dalam pengembangan desain kemasan yang lebih aman dengan melibatkan semua pihak yang berkaitan termasuk konsumen. Saat ini CV Frinsa Agrolestari telah mengemas biji kopinya yang berukuran $1 \mathrm{~kg}, 3 \mathrm{~kg}$, dan $5 \mathrm{~kg}$ dengan meggunakan vacuum sealing untuk menjaga kualitas dan kesegaran biji kopinya. Namun pengemasan dengan cara vacuum sealing ini juga menimbulkan masalah baru karena kemasan menjadi lebih rentan pecah. Oleh karena itu, CV Frinsa Agrolestari perlu mengembangkan teknik pengemasan dalam pengiriman yang lebih aman dan tidak mudah pecah tapi tetap menjaga kualitas biji kopinya. $\mathrm{Hal}$ ini dapat dilakukan dengan mencari bahan kemasan yang tahan terhadap benturan dan lentur, menambahkan busa atau bubble wrap untuk mengurangi dampak benturan, dan sebagainya.

ST3: Edukasi konsumen mengenai kualitas produk

Strategi ini merupakan pewujudan dari strategi intensif yaitu pengembangan pasar serta strategi integrasi yaitu integrasi maju. Produk niche market berarti konsumen sudah atau mau teredukasi mengenai produk tersebut, tidak terkecuali produk biji kopi specialty. Setiap konsumen sudah memiliki preferensi karakteristik biji kopi specialty tertentu yang diinginkan. Namun demikian, tetap tidak menutup kemungkinan untuk memperluas pasar tersebut ke konsumen baru. Oleh karena itu, edukasi product knowledge kepada masyarakat tetap menjadi sarana perluasan cakupan pemasaran yang ideal. Edukasi tersebut dapat dilakukan secara langsung seperti pada pameran atau acara-acara lainnya maupun secara daring melalui media sosial. Dalam strategi ini, konsep 4C conversation memiliki peran penting. Selain perusahaan dapat menyampaikan informasi terkait kopi dan prosesnya, konsumen juga dapat aktif bertanya mengenai informasi-informasi apa saja yang ingin diketahui, dengan begitu $\mathrm{CV}$ Frinsa Agrolestari akan mampu menyampaikan informasi dengan tepat sasaran.

\section{Strategi WT (Weaknesses - Threats)}

WT1: Pengoptimalan pengembangan proses produksi dan bisnis

Salah satu perbaikan yang perlu dilakukan oleh CV Frinsa Agrolestari adalah pengoptimalan proses produksi. CV Frinsa Agrolestari memiliki mesin pemrosesan biji kopi dengan kapasitas mencapai 1000 ton per tahunnya, namun hingga saat ini CV Frinsa Agrolestari baru mampu memproduksi sebanyak 100-150 ton saja per tahunnya atau sekitar 10-15 persen dari kapasitas totalnya saja. Sehingga dapat dilihat bahwa CV Frinsa Agrolestari memiliki kapasitas yang mencukupi untuk perkembangan dalam proses produksi. Dengan pengoptimalan proses bisnis dan produksi, CV Frinsa Agrolestari akan mampu mengefisienkan penggunaan sumber daya yang dimiliki sehingga dapat menurunkan biaya produksi. Strategi ini merupakan aplikasi dari konsep $4 \mathrm{C}$ co-creation dan conversation. Strategi ini merupakan pewujudan dari strategi intensif yaitu pengembangan produk serta strategi integrasi yaitu integrasi mundur. 


\section{PENUTUP}

Strategi pemasaran yang sudah diterapkan oleh CV Frinsa Agrolestari adalah menjalin hubungan baik dengan mitra, konsumen, program sosial, serta asosiasi dan komunitas kopi; proses berbasis value produk; product co-creation dengan konsumen; produk berstandar SCA dan SNI; dan range ukuran kemasan banyak.

Berdasarkan hasil analisis faktor lingkungan internal CV Frinsa Agrolestari, terdapat sebelas faktor strategis internal dengan kekuatan utama adalah product cocreation dengan konsumen dengan skor 0.406 sedangkan kelemahan utama CV Frinsa Agrolesetari adalah penggunaan kapasitas mesin produksi belum optimal dengan skor 0.086. Berdasarkan hasil analisis faktor lingkungan eksternal CV Frinsa Agrolestari, terdapat enam faktor strategis eksternal dengan peluang terbesar CV Frinsa Agrolestari pertumbuhan niche market dengan skor 0.711 sedangkan ancaman terbesar CV Frinsa Agrolesetari adalah fluktuasi harga kopi global dengan skor 0.289.

Berdasarkan matriks IE, CV Frinsa Agrolestari berada di sel IV (grow and build) sehingga strategi intensif (pengembangan produk, pengembangan dan penetrasi pasar) dan strategi integratif (integrasi horizontal dan integrasi mundur serta integrasi maju) merupakan alternatif strategi yang dapat disarankan untuk diimplementasikan. Berdasarkan analisis matriks SWOT, didapatkan 7 rekomendasi strategi pemasaran yaitu: (SO1) Melakukan pengembangan produk secara terus-menerus, (SO2) Pengembangan bisnis ekowisata dan eduwisata sebagai media pemasaran, (SO3) Pengembangan bisnis kopi hilir, (WO1) Pengoptimalan penggunaan internet sebagai media pemasaran, (ST1) Komunikasi yang intensif dengan konsumen dan jasa ekspedisi, (ST2) Pengembangan desain kemasan yang lebih aman, (ST3) Edukasi konsumen mengenai kualitas produk, dan
(WT1) Pengoptimalan pengembangan proses produksi dan bisnis.

Penelitian lanjutan mengenai strategi pemasaran CV Frinsa Agrolestari yang mencakup wilayah lebih luas sehingga lebih mereprentasi semua konsumen CV Frinsa Agrolestari. Selain itu, dapat dikaji mengenai prioritas penerapan alternatif strategi yang diperoleh.

\section{REFERENSI}

Booms B, Bitner MJ. (1981). Marketing strategies and organizational structures for service firms. J.H. Donnelly, W.R. George (Eds.), Marketing of services, American Marketing Association, Chicago, IL, pp. 47-51

David FR. (2011). Strategic Management: CONCEPTS AND CASES. New Jersey (US): Pearson Education, Inc.

Ganda H. (2003). Analisis Perilaku Konsumen Kopi Serta Implikasinya Terhadap Strategi Pemasaran Produk Kopi Sabani. [Skripsi]. Institut Pertanian Bogor. Tersedia pada: https://repository.ipb.ac.id/bitstream/h andle/123456789/17451/A03hga.pdf?s equence $=2 \&$ isAllowed $=y$

Hennig-Thurau T, et al. (2010). The impact of new media on customer relationships Journal of Service Research, 13 (3), pp. 311-330

Herlyana E. (2012). Fenomena Coffee Shop Sebagai Gejala Gaya Hidup Baru Kaum Muda. [Jurnal]. THAQAFIYYAT: Jurnal Bahasa, Peradaban dan Informasi Islam. 13(1). Tersedia pada: http://ejournal.uinsuka.ac.id/adab/thaqafiyyat/article/ view/43 [diunduh 2019 Agustus 9].

Hikmah PN. (2019). Strategi Pemasaran Kopi Spectrum di Kota Bogor. [Skripsi]. Institut Pertanian Bogor. Tersedia pada: https://repository.ipb.ac.id/handle/123 456789/97922 
[ICO] International Coffee Organization. (2019). Total production by all exporting countries. [Internet]. Tersedia pada: http http://www.ico.org/prices/poproduction.pdf [diunduh 2019 Juni 15].

[ICO] International Coffee Organization. (2019). World coffee consumption. [Internet]. Tersedia pada: http://www.ico.org/prices/newconsumption-table.pdf [diunduh 2019 Juni 15].

Jati, YP. (2006). Analisis Nilai tambah dan strategi pemasaran kopi bubuk arabika kelompok tani manunggal VI Kecamatan Jambu Semarang. [Skripsi]. Institut Pertanian Bogor. Tersedia pada: https://repository.ipb.ac.id/bitstream/h andle/123456789/50982/A06ypj.pdf?se quence $=1$ \&is $A$ llowed $=y$

Kotler P, Keller KL. (2012). Marketing management (15th ed.), Prentice Hall, Upper Saddle River, NJ. , Amstrong G. (2012). Principles of Marketing 14th Ed. Amerika (US): Pearson Education, Inc. , Kartajaya H, Setiawan I. (2017). Marketing 4.0: Moving from Traditional to Digital. Hoboken (US): Wiley.

Lo F, Campos N. (2018). Blending Internet-ofThings (IOT) Solutions into Relationship Marketing Strategies. Technological Forecasting \& Social Change 137 (2018) 10-18.
McCarthy JE. (1960). Basic marketing. A managerial approach. Richard D. Irwin, Homewood, IL (US).

Pelsmacker PD, et al. (2010). Marketing Communications: A European Perspective $4^{\text {th }}$ Edition. Pearson Education Limited. Harlow: UK.

Plume CJ, et al. (2017). Social Media in the Marketing Context: Chapter 2 The New Marketing Environment. A State of the Art Analysis and Futur Directions 2017. pp. 7-40

Rizqi N. 2018. Strategi Pengembangan Agribisnis Kopi Arabika di Kabupaten Banjarnegara Jawa Tengah. [Skripsi]. Institut Pertanian Bogor. Tersedia pada: https://repository.ipb.ac.id/handle/123 456789/93871

[SCA] Specialty Coffee Association. (2018). Coffee standards [internet]. Tersedia pada: https://sca.coffee/ research/coffee-standards [diunduh 2019 Juli 06].

Sepulveda WS, et al. (2016). Consumers' preference for the origin and quality attributes associated with production of specialty coffees: Results from a crosscultural study. Food Research International 89 (2016) 997-1003.

Yusianto. (2013). Karakteristik kopi Indonesia Juni 2013 [internet]. Tersedia pada: http://agro.kemenperin.go.id/ media/download/465 [diunduh 2019 Agustus 18]. 